\title{
Tradeoff Study between Cost and Environmental Impact of Aircraft Using Simultaneous Optimization of Airframe and Engine Cycle
}

\author{
Xiao Chai, Xiongqing Yu, and Yu Wang \\ Key Laboratory of Fundamental Science for National Defense-Advanced Design Technology of Flight Vehicle, \\ College of Aerospace Engineering, Nanjing University of Aeronautics and Astronautics, Nanjing 210016, China
}

Correspondence should be addressed to Xiongqing Yu; yxq@nuaa.edu.cn

Received 12 December 2016; Accepted 26 April 2017; Published 25 May 2017

Academic Editor: Kenneth M. Sobel

Copyright (C) 2017 Xiao Chai et al. This is an open access article distributed under the Creative Commons Attribution License, which permits unrestricted use, distribution, and reproduction in any medium, provided the original work is properly cited.

\begin{abstract}
To investigate more efficient aircraft configurations which have less environmental impact, this paper develops a multidisciplinary analysis framework integrated with the airframe and propulsion analysis modules. The characteristics for propulsion, aerodynamics, weight, performance, cost, emissions, and noise can be rapidly predicted by the framework. The impact of propulsion installation with large diameter engines on aircraft weight and drag are considered in the framework. A wide-body aircraft was taken as an example for the optimization to investigate the tradeoffs between the cost metric and the environmental performance metrics. Several cases for single objective and multiobjective optimizations were performed. In the single objective optimizations, the direct operating cost, the cumulative noise, the oxides of nitrogen emissions during landing-takeoff cycle, and the mission oxides of nitrogen emissions were considered as an objective and minimized, respectively. The different objectives resulted in designs with different airframe parameters and engine cycle parameters. In the multiobjective optimizations, the direct operating costs and environmental performances were considered as the objectives simultaneously. The optimization results were the Pareto fronts for the minimum direct operating costs and environmental performances, which illustrate the quantitative relationships between the economic metric and the environmental performances.
\end{abstract}

\section{Introduction}

The environmental impact of aircraft has become critical in commercial aviation with the continuous growth in air traffic and increasing public awareness. According to the International Civil Aviation Organization (ICAO) reports, the civil air transport is expected to continue to increase at an average annual rate of $4.8 \%$ through 2036 [1]. The continuing growth in air traffic has caused the increasing environmental impact in terms of noise, air quality, and climate change. The contribution to global anthropogenic carbon emissions by aviation may increase to $15 \%$ by 2050, as suggested in the 1999 Intergovernmental Panel and Climate Change (IPCC) report [2].

NASA's Environmentally Responsible Aviation (ERA) $\mathrm{N}+2$ project has set aggressive goals in the areas including a noise goal of $42 \mathrm{~dB}$ cumulative below Stage 4 certification level. The goal for the reduction of oxides of nitrogen is
$75 \%$ below the current standard. The fuel burned reduction goal is $50 \%$ below that of a current state-of-the-art aircraft [3]. European "Clean Sky 2" program has also set ambitious targets in the reduction of $\mathrm{CO}_{2}$ and oxides of nitrogen ( $\left.\mathrm{NO} x\right)$ emissions and noise abatement [4].

Some methods of aircraft conceptual design have been developed to achieve these aggressive, however, often conflicting goals. Traditional methods, in which the analysis and optimization of propulsion system and airframe are handled separately, are hard to further improve aircraft performance and to satisfy the stringent environmental constraints. To develop more efficient aircraft configurations which have minimal environmental impact, the design of airframe and propulsion system must all be considered simultaneously at the early phases of the design process [5]. Simultaneous optimization of airframe and engine in the aircraft conceptual design phase allows designer to explore the different aircraft 


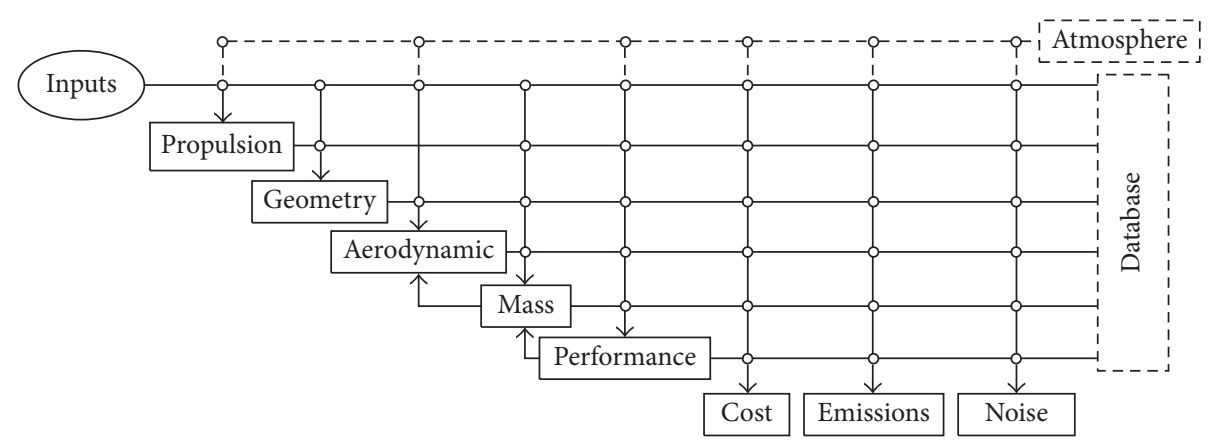

FIGURE 1: Framework of multidisciplinary analysis.

configurations and engine and to investigate the tradeoffs between costs and environmental performance metrics [6].

Much work has been done on the subject of directly combining engine cycle analysis and optimization with aircraft design and optimization. Lavelle et al. [7] developed an Integrated Propulsion/Airframe Analysis System (IPAS) for the multidisciplinary analysis and optimization of airframe and propulsion design parameters. Antoine and Kroo $[8,9]$ used genetic algorithms to optimize the aircraft for minimum cost, noise, and NOx emissions. Multiobjective optimization was also performed to find out the tradeoffs between conflicting objective metrics. Schwartz and Kroo [10] presented a climate model and optimized the aircraft with respect to aircraft cost, fuel burned, and NO $x$ emissions. Henderson et al. [11] performed single and multiobjective optimizations on the multiple aircrafts to investigate the tradeoffs between the various environmental performance metrics. Wang et al. [12] presented an approximate sensitive analysis and a multiobjective optimization of aircraft design for tradeoff between greenhouse effect and direct operating cost (DOC).

However, some shortcomings exist in current researches: (1) the method used to calculate emission performance is Boeing fuel flow method, which is unable to reflect the effects of engine cycle parameters; (2) the noise analysis module does not account for the engine equipped with liner and chevron nozzle that suppress aircraft noise; (3) there was no attention paid to the issue that landing gear needs to be lengthened due to the higher bypass ratio engine to ensure the engine ground clearance and that the engine should not be damaged when the nose gear collapses.

To overcome the above shortcomings, a multidisciplinary analysis framework integrating airframe and propulsion system was developed in this study, in which the analysis modules for emissions and noise and landing gear weight have been improved to address the above problems. Based on the multidisciplinary analysis framework, the single and multiobjective optimizations were performed on a baseline aircraft to investigate the tradeoffs between the cost metric and the various environmental performance metrics. The metrics of interest include the direct operating cost, landing-takeoff (LTO) cycle NOx emissions, total mission NO $x$ emissions, and aircraft certification noise [3].

\section{Methodology}

The multidisciplinary integrated analysis framework for aircraft conceptual design consists of a number of analysis modules, including propulsion, geometry, aerodynamics, weight, mission performance, cost, noise, and emissions modules [13], as shown in Figure 1. For considerations of rapid execution and robustness of the framework, empirical formulations with various statistical data, semiempirical equations, and the simplified numerical methods are used in the modules. Each module is independent and easy to be modified and improved. The details of each discipline are described in the following.

2.1. Propulsion. The propulsion module is used to predict thrust, fuel flow performance, and the thermodynamic properties of each component of the engine, which are needed in the noise and emissions analysis modules. The basic engine architecture for the optimization performed in this study is a two-spool, separate flow turbofan as shown in Figure 2.

The code for calculating the performance is a zerodimensional steady thermodynamics analysis program [14]. At the design point, the program automatically ensures continuity of mass, speed, and energy by varying the scale factors on the performance maps for the compressor and turbine components. Off-design operation is handled through the use of component performance tables and minimization of work, flow, and energy errors. The component performance tables for the off-design operating conditions are from NLR GSP 11 [15]. The engine is then balanced by altering the free variables of available components. The internal performance and drag of inlet and nozzle are estimated according to [16]. An empirical method is used to estimate the size and weight of the propulsion system [17].

The results of engine performance are exported in a three-dimensional array of altitude, Mach number, and thrust settings. In order to improve the computational efficiency, the envelope for engine performance calculation is the same as the aircraft flight envelope. The typical thrust settings are considered in the propulsion module, including the 


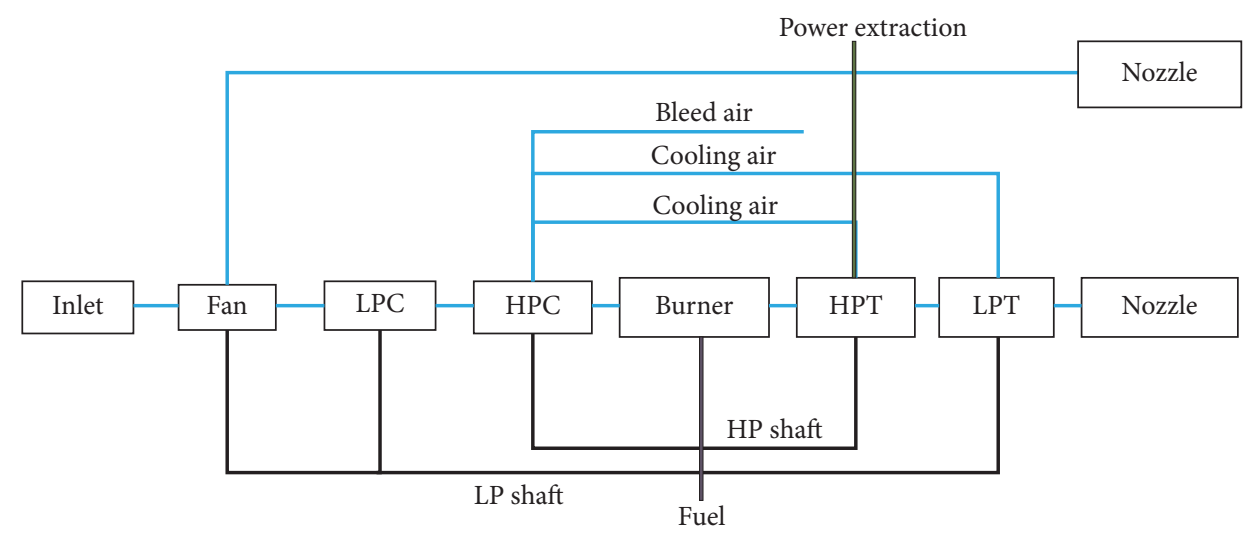

FIgure 2: Turbofan engine model with two-spool separate exhaust.

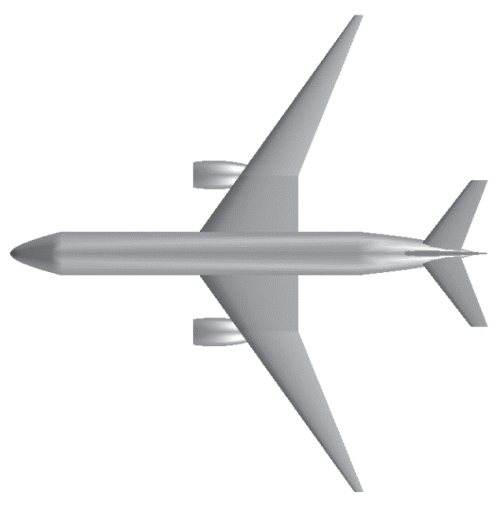

FIgURE 3: A typical geometrical model of aircraft configuration.

settings for maximum takeoff, maximum climb, maximum continuous, maximum cruise, and idle thrust.

2.2. Geometry. A parametric geometry model is used to define the aircraft configuration geometry. The $3 \mathrm{D}$ geometrical model of aircraft configurations can be generated by the parametric aircraft geometry model. The inputs are each of component geometry parameters of the aircraft and their position parameters. The outputs are the wetted area of each component of the aircraft and the available volume for the fuel tank. A typical geometrical model of aircraft configuration is shown in Figure 3. The quasianalytical methods [18] are used to estimate the wetted area of the aircraft and the volume for the fuel tank. The function of geometry model is to provide all geometry information to other analysis modules.

2.3. Aerodynamics. The aerodynamics module is used to predict the low-speed and high-speed aerodynamic characteristics of the aircraft. There are various formulations of aerodynamics analysis for conceptual design from different references. In our past works, we have used the aerodynamic data [19] of the typical civil aircraft to validate those analysis models in terms of accuracy and computational burden. Based on our validation results, we selected the aerodynamics analysis models which are most appropriate for the aircraft conceptual design stage. The criteria for selecting the aerodynamics analysis models are the satisfactory accuracy and fast response. The limitation for the selected models is that they can only be used for conventional configuration aircraft.

The lift characteristics of a clean wing are computed using a quasianalytical technique [18]. The zero-lift drag is calculated using a detailed component build-up method [20], which takes into consideration the viscous separation and mutual interference effects between components. The liftinduced drag is Oswald Span Efficiency Method [18]. The wave drag is modeled based on modified Korn's equation offered by Torenbeek [21]. The lift increment produced by flap and slat deflections at the low-speed is estimated based on the methods presented by Isikveren [18]. Total incremental drag due to one engine inoperative condition is also estimated in this module.

2.4. Weights. The aircraft takeoff weight is calculated iteratively by adding the component weight, which is estimated using statistical models [22] required for the mission. Figure 4 illustrates the definition and breakdown of aircraft weight.

A landing gear analysis model in the weight module is developed to estimate the weight and size of landing gears [23]. Except for conventional constraints considered in landing gears design, two additional constraints are highlighted here to take into account the influence by high bypass ratio engine. The first constraint is that the requirement for a minimum nacelle ground clearance should be satisfied. The second constraint is that the potential of engine damage in the case of a nose gear collapse should be avoided.

The main landing gear length $L_{1}$ required to meet the minimum nacelle ground clearance $z_{\min }$ is a function of the nacelle maximum diameter $D_{\mathrm{mh}}$, the spanwise location of the nacelle $y_{\text {nac }}$, the wing dihedral $\Gamma$, the spanwise location of the main gear $y_{\text {gear }}$, and the "nacelle-wing offset" $\Delta z_{\text {nac }}$, defined here as the vertical distance between the top of the nacelle and the local wing chord line [24], as shown in Figure 5.

$$
L_{1}=z_{\text {min }}+D_{\text {mh }}-\left(\left(y_{\text {nac }}-y_{\text {gear }}\right) \tan (\Gamma)-\Delta z_{\text {nac }}\right) .
$$

The main landing gear length necessary to avoid engine damage in the case of nose gear collapse is dependent on the 


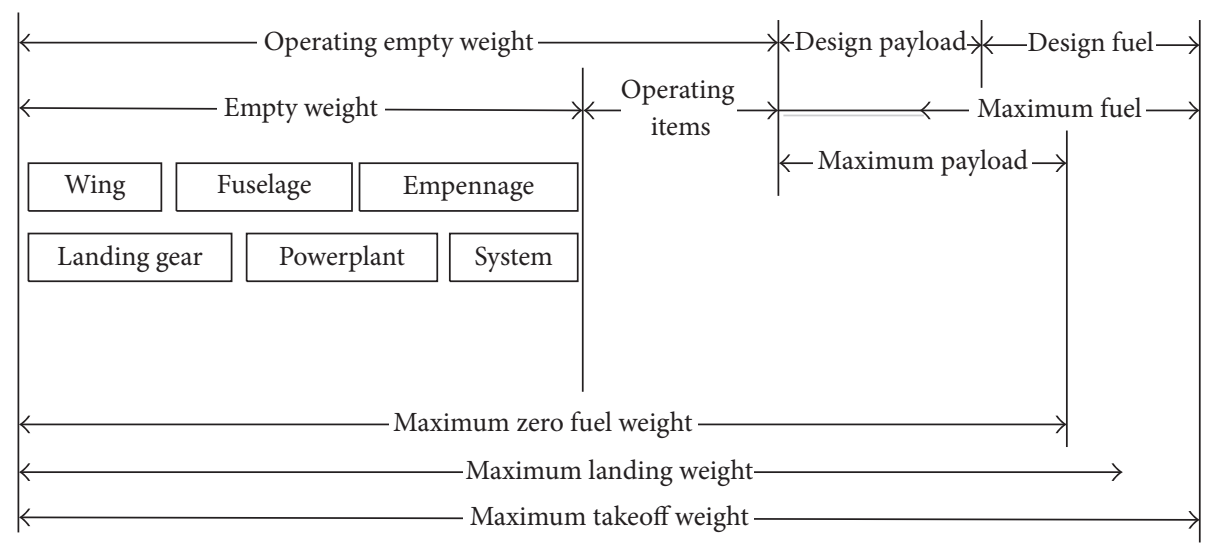

FIGURE 4: Aircraft weight breakdown and definition.

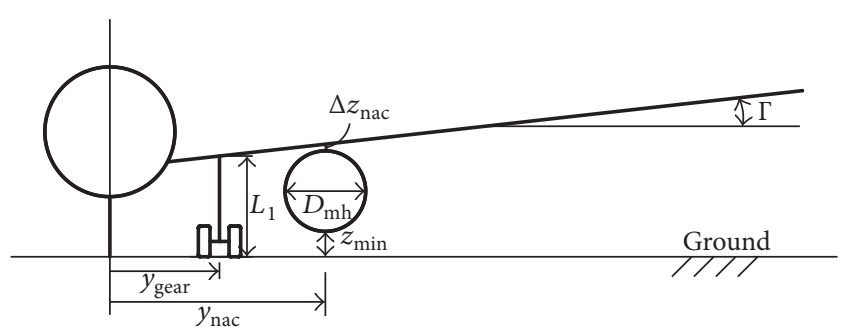

FIgURE 5: Nacelle ground clearance geometry.

overall geometric layout of the airplane. Additional relevant geometric parameters include horizontal distance between the nacelle maximum diameter point (ground contact point) and the main landing gear ground contact point, $\Delta x_{\text {nac }}$; horizontal distance between the lowest forward fuselage point and the main landing gear contact point, $\Delta x_{\text {fus }}$; vertical distance between the main landing gear attachment point and the lowest forward fuselage point, $\Delta z_{\text {fus }}$. These parameters are illustrated in Figure 6. The required main landing gear length, $L_{2}$, is given by [24]

$$
\begin{aligned}
L_{2} & =\frac{1}{\left(1-\Delta x_{\text {nac }} / \Delta x_{\text {fus }}\right)} \times\left(D_{\text {mh }}-\left(\frac{\Delta x_{\text {nac }}}{\Delta x_{\text {fus }}}\right) \Delta z_{\text {fus }}\right. \\
& \left.-\left(\left(y_{\text {nac }}-y_{\text {gear }}\right) \tan (\Gamma)-\Delta z_{\text {nac }}\right)\right) .
\end{aligned}
$$

The final main landing gear length estimated was based on the larger of $L_{1}$ and $L_{2}$. Since these lengths are from the main landing gear ground contact point to the attachment point, in a compressed state, to arrive at the extended strut length, the tire radius was subtracted and the length was increased by $20 \%$.

2.5. Performance. The performance module estimates mission fuel burned, takeoff field length, landing field length, and the second segment gradient. A typical airliner mission profile is illustrated in Figure 7. The takeoff and landing performance are calculated using a parametric expression [17]. The flight main mission performance is obtained using
TABLE 1: Results of DOC components for baseline aircraft.

\begin{tabular}{lcc}
\hline Component & $\begin{array}{c}\text { Costs } \\
(\mathrm{RMB} / \mathrm{PAX} / \mathrm{km})\end{array}$ & $\begin{array}{c}\text { Fraction of total DOC } \\
(\%)\end{array}$ \\
\hline Depreciation & 0.061228 & 19.53 \\
Interest & 0.019845 & 6.33 \\
Insurance & 0.011443 & 3.65 \\
Crew & 0.011380 & 3.63 \\
Fuel & 0.116280 & 37.09 \\
Maintenance & 0.055428 & 17.68 \\
Airport fees & 0.032981 & 10.52 \\
Navigation fees & 0.004922 & 1.57 \\
\hline DOC & 0.31351 & 100 \\
\hline
\end{tabular}

a piecewise analytic model based on the simplified motion equations for the typical flight segments [25]. The fuel burned in reserve mission is based on fraction of the aircraft maximum takeoff weight. Additional performance constraints in the optimization problems are also evaluated in the performance module.

2.6. Cost. The direct operating cost (DOC) is used as the economic figure of merit in this paper and expressed as the cost per passenger-kilometer flown [26]. The DOC is divided into two categories, ownership cost and cash cost. The ownership cost includes depreciation, interest, and insurance. The cash cost represents the cost of operating the aircraft in scheduled service, and includes flights and cabin crew wages, engine and airframe maintenance, fuel cost, navigation fees, and airport landing fees. Figure 8 shows the components making up the DOC for the study aircraft.

In the DOC calculation, some assumptions are made according to current commercial aviation market in China. The useful life of a civil aircraft is 20 years, residual value is $5 \%$, the loan period is 11 years, the fuel price is $\mathrm{RMB}$ 6 Yuan $/ \mathrm{kg}$, the utilization of the airplane is 4000 hours per year, and the calculation range is 3000 nautical miles. Most of these parameters are time-dependent due to the economic effect. Table 1 shows the results of DOC components for baseline aircraft. The aircraft parameters influencing DOC 


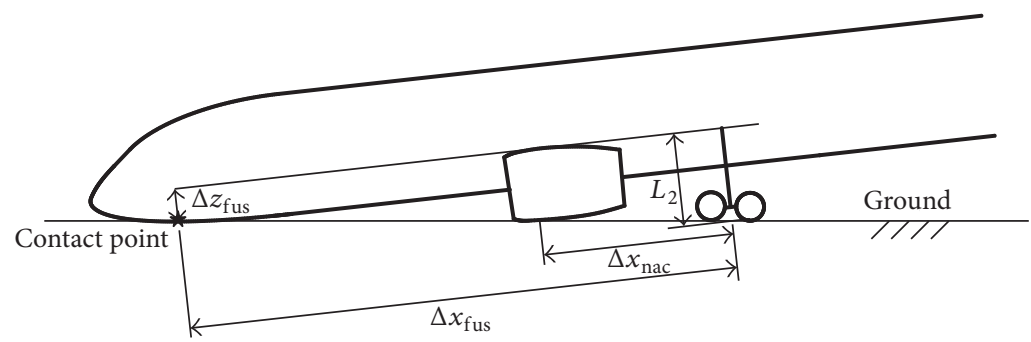

FIGURE 6: Nose gear collapse geometry.

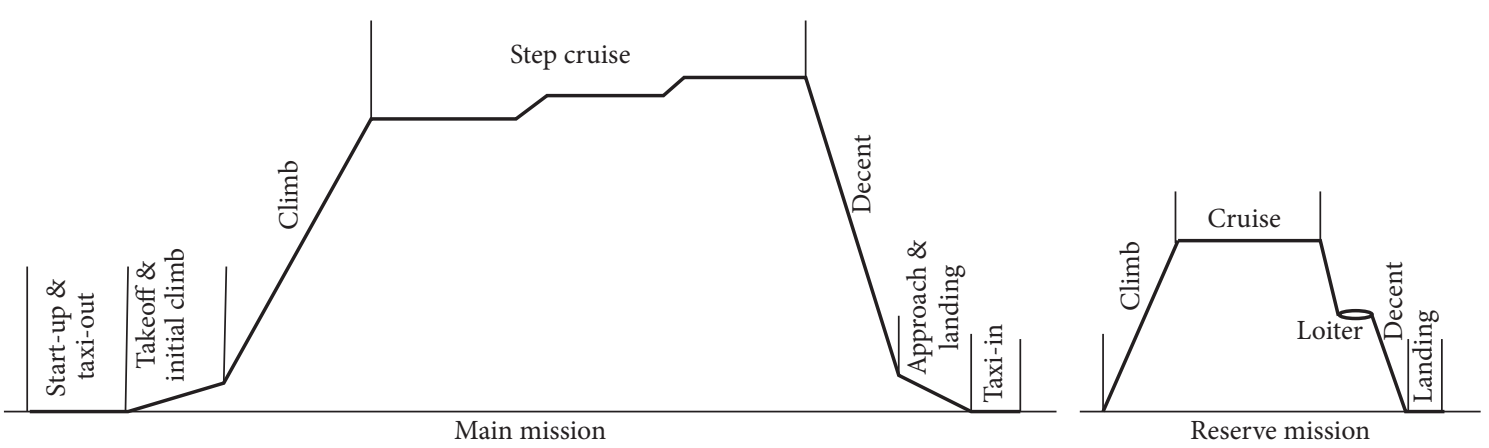

FIGURE 7: Typical airliner mission profile.

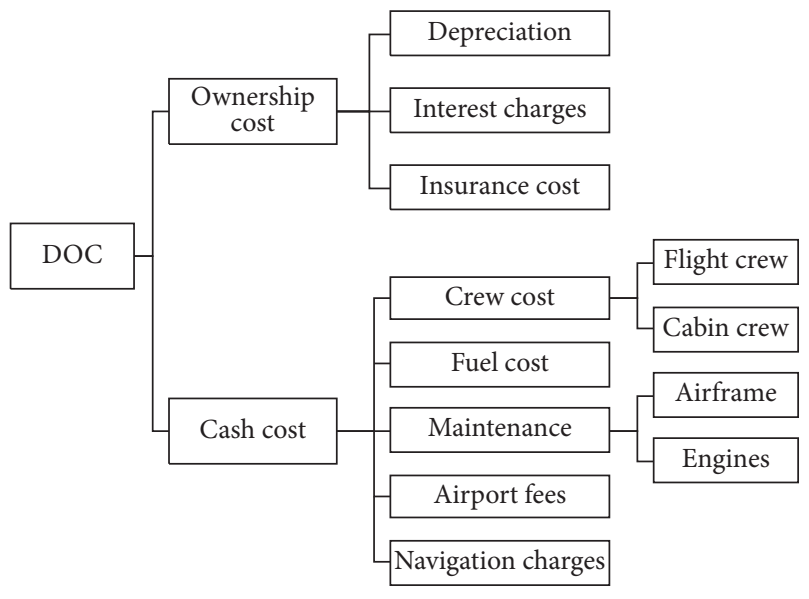

FIgURE 8: Direct operating cost components.

mainly include block fuel, the weight of the aircraft, and the maximum thrust of the engine in current study.

2.7. Emissions. Current ICAO regulations restrict the landing-takeoff (LTO) cycle $\mathrm{NO}_{x}$, CO, unburned hydrocarbons, and smoke emissions [27]. There is considerable pressure to further reduce $\mathrm{NO} x$ emissions from all sources; therefore the emissions module here focuses on calculating both LTO cycle $\mathrm{NO}_{x}$ emissions and total mission $\mathrm{NO}_{x}$ emissions, as this is likely to become another area of regulatory focus. The $T_{3}-P_{3}$ method is used to calculate the emissions [28].

The $\mathrm{NO}_{x}$ emissions can be computed by multiplying the fuel-specific emission index $\left(I_{e, \mathrm{NO} x}\right)$, the fuel flow $(\dot{m})$, and
TABLE 2: ICAO landing-takeoff cycle.

\begin{tabular}{lcc}
\hline Engine modes & Thrust setting (\%) & Time (min) \\
\hline Takeoff & 100 & 0.7 \\
Climb out & 85 & 2.2 \\
Approach & 30 & 4.0 \\
Idle & 7 & 26.0 \\
\hline
\end{tabular}

the flight time $(\Delta t)$ for each segment $i$ and adding them as follows:

$$
E_{\mathrm{NO} x}=\sum_{i=1}^{N} I_{e, \mathrm{NO} x, i} \times \dot{m}_{i} \times \Delta t_{i}
$$

The $\mathrm{NO}_{x}$ emission index is dependent on the thrust setting and can be predicted using a correlation that depends on the flow conditions, both downstream and upstream of the combustor. The correlation is given by

$$
I_{e, \mathrm{NO} x}=0.004194 T_{4}\left(\frac{P_{3}}{439}\right)^{0.37} \exp \left(\frac{T_{3}-1471}{345}\right),
$$

where $P_{3}$ is the combustor entrance absolute pressure in psi and $T_{3}$ and $T_{4}$ are the entrance and exit combustor temperatures, respectively, in Rankine.

Then the LTO $\mathrm{NO}_{x}$ emissions can be computed based on the thrust setting and flight time defined by ICAO [27] and shown in Table 2. Total mission $\mathrm{NO}_{x}$ emissions are obtained in the same ways based on the emission index, the fuel flow, and the flight time for each segment.

2.8. Noise. Aircraft noise is composed of engine noise and airframe noise. For certification purposes, a commercial 


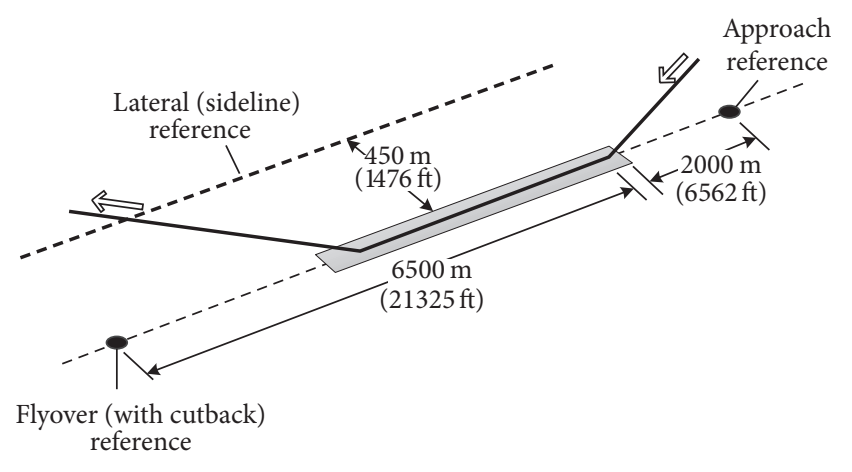

FIGURE 9: Noise certification points.

aircraft must meet FAA Part 36 regulations, based on ICAO Annex 16 guidelines [29]. Noise certification is issued based on the measurements at three points during the takeoff and the landing procedures as shown in Figure 9. The Effective Perceived Noise Level (EPNL) is calculated at the noise certification point, which is an integration of the ground observer perceived noise time history that depends on aircraft trajectory, noise spectra propagation, frequency integration, and tonal content and amplitude penalties.

Generally, the noise prediction tools can be assigned to three major categories: empirical, semiempirical, and numerical methodologies [30]. The tool used in the noise analysis module is based on semiempirical but physics-based approximations [31]. This noise prediction tool can account for the specific operational conditions along a simulated flight and the component's geometry. The tool incorporates publicly available noise prediction schemes [31] and is updated. As part of this paper, three noise sources are considered: fan, jet, and airframe. Other noise sources, such as combustion, turbines, and compressors, are not considered because of their relatively minor contribution to total aircraft noise for most engines.

A flow chart of the noise prediction program is shown in Figure 10. The procedure begins with defining an atmosphere using the Atmosphere Module (ATM), followed by the atmospheric absorption module (ABS). The steady flyover module (SFO) is used for the approach measurement point and the jet takeoff module (JTO) for sideline and takeoff measurement points. The engine module (ENG) computes component thermodynamic properties of the engine. The geometry module (GEO) provides the range and directivity angles from the observer to the noise source. At this point, the various noise source prediction modules used state-of-the-art methodologies are run. The liner module (LINER) is used to model the fan inlet and fan exhaust suppression by liners [32]. Heidmann's new modified method (HDNFAN) is used for fan noise prediction [33]. Stone's new method (STN2JET) is used for coaxial jet noise prediction, which takes into account of the suppression by chevron nozzle [34]. Fink's method (FNKAFM) is used for airframe noise prediction [35]. The propagation module (PRO) applies corrections to the noise data in the source frame of reference to transfer it to the observer frame of reference. The noise levels module (LEV) computes the Tone-corrected Perceived Noise (PNLdB), and the effective noise level module (EFF) is run next to compute the EPNLdB levels as noise metrics in this paper.

\section{Optimization}

Currently, China and Russia are codeveloping wide-body aircraft [36], and the design study for this type of aircraft is more interested to us. Therefore, a notional 280-passenger wide-body aircraft is taken as an example for the optimization to investigate the tradeoffs between the cost metric and the environmental performance metrics based on the above framework. The design range of the aircraft is 12000 kilometers and the cruise Mach number is 0.85 , which are chosen the same as that of the aircraft which is being codeveloped by China and Russia [36].

\subsection{Problem Formulations}

3.1.1. Design Variables. The design variables in the optimization include airframe geometry parameters and engine thermodynamic cycle parameters. The design variable and their respective bounds are listed in Table 3. The initial values came from a conceptual design study conducted by designers from the industry.

3.1.2. Constraints. There are several constraints imposed in the optimization problems, which are listed in Table 4. These constraints ensure that the optimized aircraft meet certain geometry, takeoff, climb, and landing requirements.

3.1.3. Objectives. Two kinds of objectives are considered in this study.

(1) The Aircraft Is Optimized with the Single Objective. The objective in the optimization is to minimize DOC, cumulative noise, LTO NO $x$ emissions, and mission NOx emissions, respectively. The purpose of this study is to illustrate the impacts of the different objectives on design of the airframe geometry parameters and engine thermodynamic cycle parameters.

(2) The Aircraft Is Optimized with Two Objectives including $D O C$ and Environmental Performance. The purpose of this study is to illustrate quantitative relationships between the economic metric and the environmental performances.

The optimization results are stated as follows.

3.2. Optimizations with Single Objective. In this section the aircraft is optimized for minimum DOC, minimum cumulative noise, minimum LTO NOx emissions, and minimum mission NOx emissions, respectively. A multi-island genetic algorithm (MIGA) [37] is used to solve these optimization problems. Table 5 lists the optimal design variable values for each case, as well as additional key performance parameters. Comparisons of single objective optimal designs against the baseline are illustrated in Figure 11.

As shown in Table 5 and Figure 11, the aircraft optimized for minimum DOC (design A) has a 5.71\% lower cost compared with the baseline aircraft. This aircraft achieves 


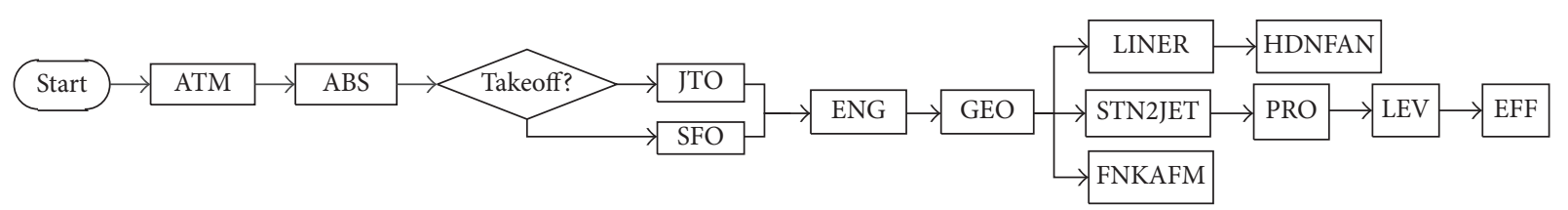

FIGURE 10: Flow chart of noise prediction program.

TABLE 3: Design variables and their bounds.

\begin{tabular}{lccc}
\hline Variable & Lower bound & Baseline & Upper bound \\
\hline Wing area $\left(\mathrm{m}^{2}\right)$ & 300 & 355.49 & 400 \\
Wing sweep $\left(^{\circ}\right)$ & 27 & 32.4 & 36 \\
Wing aspect ratio & 8 & 10.4672 & 13 \\
Wing taper ratio & 0.1 & 0.1062 & 0.12 \\
Thickness to chord ratio at wing root & 0.11 & 334 & 11 \\
\hline Maximum takeoff thrust $(\mathrm{kN})$ & 280 & 1.58 & 420 \\
Engine bypass ratio & 8 & 3.2 & 15 \\
Fan pressure ratio & 1.5 & 52 & 1.75 \\
Low-pressure compressor pressure ratio & 2.5 & 1800 & 4.5 \\
Overall pressure ratio & 40 & 1650 & 1900 \\
Turbine inlet temperature $(\mathrm{K})$ & & 500 \\
\hline
\end{tabular}

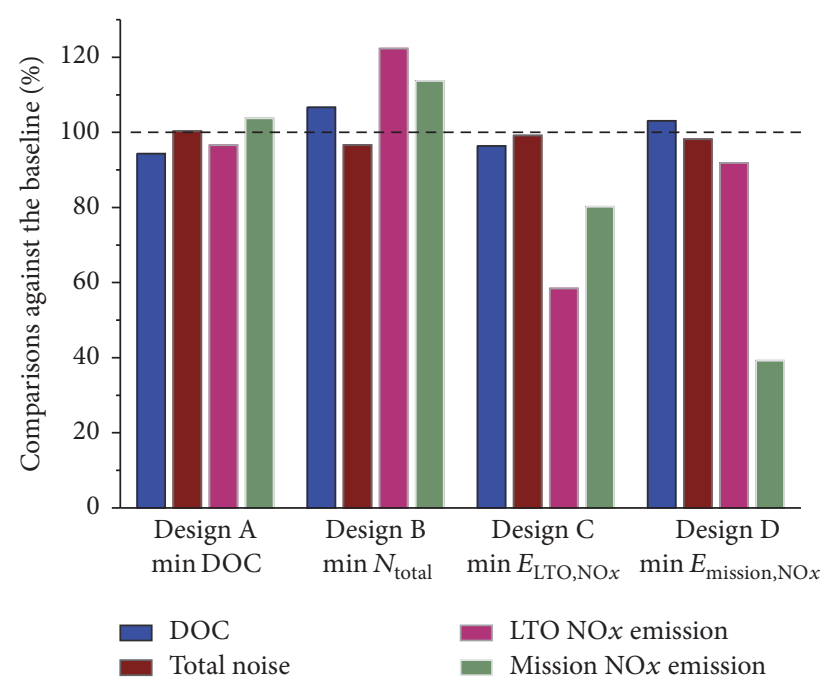

FIGURE 11: Comparisons of single objective optimal designs against the baseline.

lower DOC due to the higher aspect ratio wing, which reduces the induced drag.

The aircraft designed for minimum cumulative noise (design $\mathrm{B}$ ) has $9.4 \mathrm{~dB}$ and $10.4 \mathrm{~dB}$ reduction compared with the baseline design and design $\mathrm{A}$ (minimum DOC), respectively. But in another hand, design B (minimum noise) has a $13.15 \%$ higher cost than design A. Design B achieves such amount of cumulative noise reduction due to a higher bypass ratio engine, which reduces the jet velocity and then reduces the jet noise. The aircraft with higher bypass ratio engine needs more engine takeoff thrust to meet the takeoff filed length and engine-out climb gradient requirements, which leads to increment in the aircraft weight and a higher DOC.
TABLE 4: Optimization problem constraints.

\begin{tabular}{lc}
\hline Constraint & Value \\
\hline Design mission range $(\mathrm{km})$ & 12000 \\
Takeoff field length $(\mathrm{m})$ & $\leq 2700$ \\
Landing field length $(\mathrm{m})$ & $\leq 1750$ \\
Engine-out climb gradient & $\geq 0.024$ \\
Rate of climb at TOC $(\mathrm{m} / \mathrm{s})$ & $\geq 1.5$ \\
Fuel volume & $\geq$ required block fuel volume
\end{tabular}

Design C for minimum LTO NO $x$ emissions has $41.56 \%$ and $39.47 \%$ lower NOx emissions compared with the baseline aircraft and design A (minimum DOC), respectively. However, design C has a $2.19 \%$ higher cost than design A. Design $C$ achieves these emission reductions with a lowthrust, low temperatures and pressures engine. The decrease in temperatures and pressures can reduce the NOx emissions index.

Design D (minimum mission NOx emissions) has 60.8\% and $62.2 \%$ lower mission $\mathrm{NO} x$ emissions compared with the baseline aircraft and design A (minimum DOC), respectively. But in another hand, the cost of design $\mathrm{D}$ is $9.3 \%$ higher than design A. Design D achieves low mission NOx emissions by reducing the engine overall pressure ratio and combustor temperature, which is similar to design C (minimum LTO NO $x$ emissions). Differences between design D and design $\mathrm{C}$ are mainly that design $\mathrm{D}$ has a smaller area wing area and a larger thrust engine.

3.3. Multiobjective Optimizations. To further investigate the tradeoffs between cost and environmental performance metrics, two multiobjective optimizations studies are performed. The objectives of the first multiobjective optimization are 
TABLE 5: Results of single objective optimization cases.

\begin{tabular}{|c|c|c|c|c|c|}
\hline Parameter & Baseline & $\begin{array}{l}\text { Design A } \\
\text { min DOC }\end{array}$ & $\begin{array}{l}\text { Design B } \\
\min N_{\text {total }}\end{array}$ & $\begin{array}{c}\text { Design C } \\
\min E_{\mathrm{LTO}, \mathrm{NO} x}\end{array}$ & $\begin{array}{c}\text { Design D } \\
\text { min } E_{\text {mission, } \mathrm{NO} x}\end{array}$ \\
\hline Wing reference area $\left(\mathrm{m}^{2}\right)$ & 355.49 & 332.02 & 389.71 & 400.00 & 312.72 \\
\hline Wing sweep $\left(^{\circ}\right)$ & 32.4 & 30.46 & 29.40 & 32.88 & 28.49 \\
\hline Wing aspect ratio & 10.4672 & 12.88 & 12.94 & 13 & 12.70 \\
\hline Wing taper ratio & 0.1062 & 0.1130 & 0.1128 & 0.1004 & 0.1116 \\
\hline Ratio of thickness to chord at root & 0.135 & 0.1132 & 0.1121 & 0.1374 & 0.1117 \\
\hline Engine takeoff thrust $(\mathrm{kN})$ & 334 & 307.91 & 390.84 & 293.03 & 419.38 \\
\hline Bypass ratio & 11 & 10.70 & 13.06 & 10.25 & 8.121 \\
\hline Fan pressure ratio & 1.58 & 1.658 & 1.554 & 1.649 & 1.699 \\
\hline LPC pressure ratio & 3.2 & 4.419 & 3.768 & 2.954 & 4.418 \\
\hline Overall pressure ratio & 52 & 53.78 & 56.82 & 40.06 & 40.65 \\
\hline Turbine inlet temperature $(\mathrm{K})$ & 1800 & 1794.1 & 1787.2 & 1708.6 & 1677.7 \\
\hline Takeoff field length (m) & 2714.8 & 2670.7 & 2233.1 & 2585.4 & 2317.5 \\
\hline Landing field length (m) & 1690.8 & 1666.1 & 1582.6 & 1537.4 & 1762.2 \\
\hline Engine-out climb gradient & 0.0253 & 0.0302 & 0.0441 & 0.0241 & 0.0623 \\
\hline Rate of climb at TOC (m/s) & 2.8413 & 3.035 & 3.250 & 1.622 & 8.562 \\
\hline Maximum takeoff weight $(\mathrm{kg})$ & 230870 & 220875 & 239816 & 231857 & 227799 \\
\hline Block fuel consumption & 69661 & 62382 & 66195 & 66708 & 67431 \\
\hline $\mathrm{DOC}(\mathrm{RMB} / \mathrm{PAX} / \mathrm{km})$ & 0.31351 & 0.29560 & 0.33446 & 0.30207 & 0.32310 \\
\hline$N_{\text {total }}(\mathrm{EPLNdB})$ & 278.3 & 279.3 & 268.9 & 275.9 & 273.2 \\
\hline$E_{\mathrm{LTO}, \mathrm{NO} x}(\mathrm{~kg})$ & 7.500 & 7.241 & 9.174 & 4.383 & 6.892 \\
\hline$E_{\text {mission, } \mathrm{NO} x}(\mathrm{~kg})$ & 615.1 & 637.9 & 699.3 & 493.1 & 241.1 \\
\hline
\end{tabular}

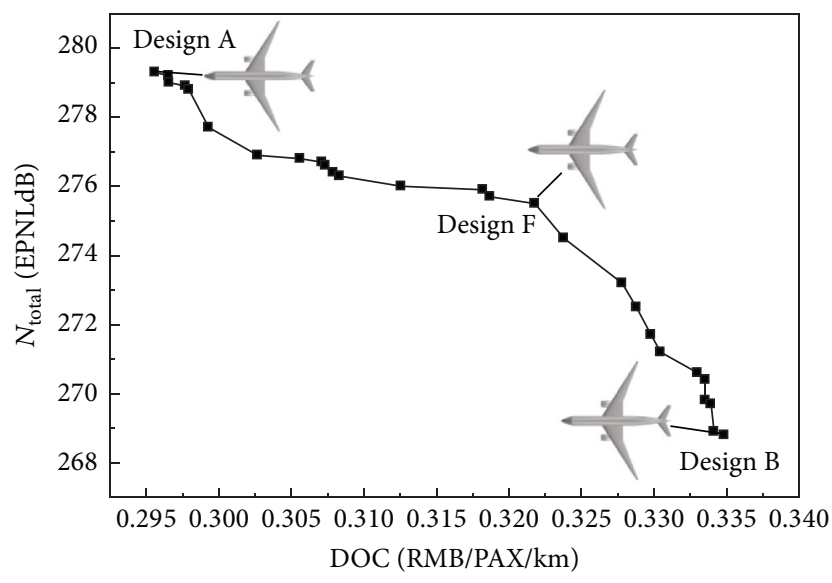

Figure 12: Pareto front for minimum DOC and $N_{\text {total }}$.

DOC and the total noise, and the objectives of the second multiobjective optimization are DOC and LTO NO $x$ emissions. The nondominated sorting genetic algorithm (NSGA II) [38] is used to solve these problems.

Figure 12 shows the Pareto front for minimizing both DOC and total noise. It shows the tradeoff between economic performance and noise performance. A planform view of three configurations is also shown in this figure. The plot also contains two optimal configurations from the single objective optimization performed above: design A (minimum DOC)

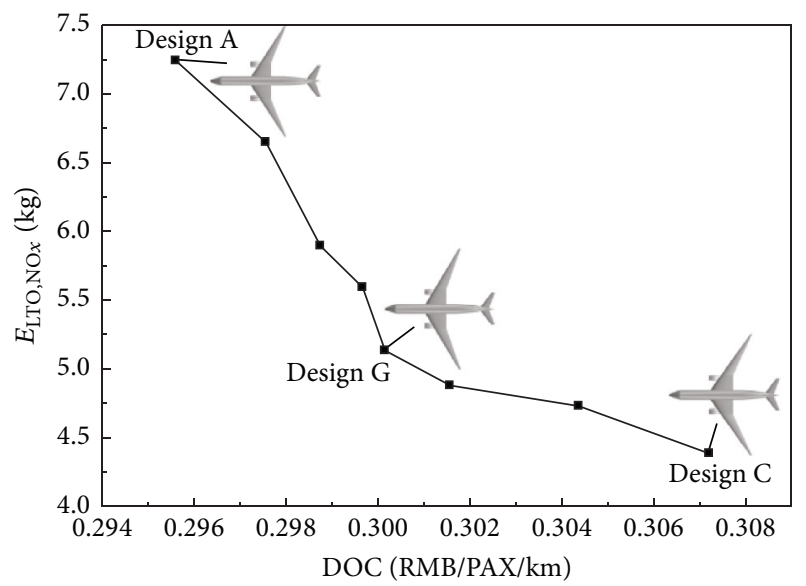

Figure 13: Pareto front for minimum DOC and $E_{\mathrm{LTO}, \mathrm{NO} x}$.

at the left most point, and design B (minimum total noise) at the far right. Design $\mathrm{F}$ is the intermediate solutions in the Figure 10. It can be seen that the total noise decreased slowly with the increase of DOC from design A to design F. But from design $\mathrm{F}$ to design $\mathrm{B}$, the reduction rate of the total noise is steeper with the increase of DOC compared with the left half segment. From design A (minimum DOC solution) to design $\mathrm{B}$ (minimum noise solution), the total noise decreases by $10.4 \mathrm{~dB}$ while DOC increases by $13.15 \%$.

Figure 13 shows the Pareto front for minimizing both DOC and LTO NO $x$ emissions. It shows the tradeoff between 
economic performance and NOx emissions. Similarly, the plot also contains two optimal configurations from the single objective optimization performed above: design A (minimum DOC) at the left most point and design $C$ (minimum total noise) at the far right. Design $G$ is the intermediate solutions in the Figure 11. It can be seen that the reduction rate of the LTO NO $x$ emissions is steeper from design A to design $\mathrm{F}$ than that from design $\mathrm{G}$ to design $\mathrm{C}$. From design A (minimum DOC solution) to design $\mathrm{C}$ (minimum LTO NO $x$ solution), the LTO NO $x$ emissions decreased by $2.858 \mathrm{~kg}$ while DOC increases by $2.19 \%$.

From Figures 11 and 12, it also can be seen that the conflict between DOC and noise is more critical than the conflict between DOC and LTO NOx emissions.

\section{Conclusions}

This paper developed a multidisciplinary analysis framework that integrates airframe and propulsion. The purpose of this research is to investigate the tradeoffs between cost and environmental performance metrics of commercial aircraft using such a multidisciplinary analysis framework. A notional wide-body commercial aircraft was used as an example for the simultaneous optimizations of airframe and engine cycle parameters, in which the direct operation cost and environmental performance metrics were minimized in the formulation of both single objective and two objectives. Some conclusions can be drawn from the results.

The different objectives resulted in designs with different airframe parameters and engine cycle parameters. The design for minimum DOC has a 5.71\% lower cost when compared with the baseline design. This is achieved by a higher aspect ratio wing with the lower induced drag. The design for minimum cumulative noise has a higher bypass ratio engine, which reduces the jet velocity and consequently reduces the jet noise. The design for minimum noise has $10.4 \mathrm{~dB}$ reduction when compared to the design with minimum DOC. The design for minimum LTO NO $x$ emissions has nearly $40 \%$ lower NOx emissions when compared with the design for minimum DOC. This design achieves these reductions with a low-thrust, low temperatures, and pressures engine. The design for minimum mission NOx emissions is similar to the design for minimum DOC because of the fact that they are all mainly determined by the fuel burned.

From the results of the multiobjective optimization for minimum DOC and environmental performance, it can be known that there exist critical conflicts between cost and environmental performance. The total noise reduction by $10 \mathrm{~dB}$ results in a large amount of DOC increase. The LTO NO $x$ emissions reduction by $2.858 \mathrm{~kg}$ results in DOC increases by $2.19 \%$.

This research indicates that the multidisciplinary analysis framework developed by this paper can be a useful tool for tradeoff study between economic and environmental performance. Current research is limited on the conventional configuration aircraft, but this analysis framework can be extended to optimized unconventional configuration aircraft such as BWB aircraft with some modifications of relevant analysis module.

\section{Conflicts of Interest}

The authors declare that there are no conflicts of interest regarding the publication of this paper.

\section{Acknowledgments}

This study was supported by the Fundamental Research Funds for Central Universities (NUAA NS2016010) and National Nature Science Foundation of China (11602103).

\section{References}

[1] International Civil aviation Organization (ICAO), "Aviation and climate change," International Civil aviation Organization (ICAO) Environmental Report, 2010.

[2] J. E. Penner, D. H. Lister, D. J. Griggs et al., Aviation and the Global Atmosphere, Cambridge University Press, Cambridge, Mass, USA, 1999.

[3] F. Collier, R. Thomas, C. Burley, C. Nickol, C.-M. Lee, and M. Tong, "Environmentally responsible aviation-Real solutions for environmental challenges facing aviation," in Proceedings of the 27th Congress of the International Council of the Aeronautical Sciences 2010 (AS '10), 2010.

[4] M. Brunet, S. Aubry, and R. Lafage, "The clean sky programme: environmental benefits at aircraft level," in Proceedings of the 15th AIAA Aviation Technology, Integration, and Operations Conference, 2015, pp. 2015-2390, usa, 2015.

[5] M. Drela, Simultaneous Optimization of The Airframe, Powerplant, And Operation of Transport Aircraft, Massachusetts Institute of Technology, Cambridge, Mass, USA, 2010.

[6] A. Seitz, S. Donnerhack, K. Broichhausen et al., "An integrated parametric model for engine and aircraft design and performance optimisation," in Proceedings of 44th AIAA/ASME/SAE/ ASEE Joint Propulsion Conference and Exhibit, 2008.

[7] T. M. Lavelle, R. M. Plencner, and J. A. Seidel, "Concurrent optimization of airframe and engine design variables," in Proceedings of the AIAA, 1992.

[8] N. E. Antoine and I. M. Kroo, "Optimizing aircraft and operations for minimum noise," in Proceedings of the AIAA's Aircraft Technology, Integration, and Operations (ATIO '02), 2002.

[9] N. E. Antoine and I. M. Kroo, "Framework for aircraft conceptual design and environmental performance studies," AIAA Journal, vol. 43, no. 10, pp. 2100-2109, 2005.

[10] E. Schwartz and I. Kroo, "Aircraft Design: Trading Cost and Climate Impact," in Proceedings of the 47th AIAA Aerospace Sciences Meeting including The New Horizons Forum and Aerospace Exposition, Aerospace Sciences Meetings, 2009.

[11] R. P. Henderson, J. R. R. A. Martins, and R. E. Perez, "Aircraft conceptual design for optimal environmental performance," Aeronautical Journal, vol. 116, no. 1175, pp. 1-22, 2012.

[12] Y. Wang, H. L. Yin, S. Zhang et al., "Multi-objective optimization of aircraft design for emission and cost reductions," Chinese Journal of Aeronautics, vol. 27, no. 1, pp. 52-58, 2014.

[13] S. Zhang and X. Q. Yu, "Sensitivity analysis of primary parameters in preliminary design of a short/medium-haul airliner," Acta Aeronautica et Astronautica Sinica, vol. 34, no. 4, pp. 809816, 2013.

[14] J. Fsellers and C. Jdaniele, "DYNGEN: a program for calculating steady-state and transient performance of turbojet and turbofan engines," NASA/TN-D-7901, NASA, 1975. 
[15] W. P. J. Visser and M. J. Broomhead, "A generic object-oriented gas turbine simulation environment," in Proceedings of the ASME Turbo Expo, 2000.

[16] J. K. Edward, "A computer code for estimating installed performance of aircraft gas turbine engines," NASA/CR-159691, NASA, Washington, DC, USA, 1979.

[17] L. R. Jenkinson, P. Simpkin, and D. Rhodes, Civil Jet Aircraft Design, Arnold, London, United Kingdom, 1999.

[18] A. T. Isikveren, Quasi-Analytical Modelling and Optimization Techniques for Transport Aircraft Design, Royal Institute of Technology, Stockholm, Sweden, 2002.

[19] E. Obert, Aerodynamic Design of Transport Aircraft, IOS press, 2009.

[20] C. R. Feagin and W. D. Morrison, "Delta method, an empirical drag buildup technique,” NASA/CR-151971, NASA, 1978.

[21] E. Torenbeek, "Optimum Wing area, aspect ratio and cruise altitude for long range transport aircraft," Report LR-775, Delft University of Technology, Faculty of Aerospace Engineering, The Netherlands, 1994.

[22] D. Howe, Aircraft Conceptual Design Synthesis, Professional Engineering Publishing Ltd, London and Bury St Edmunds, 2000.

[23] P. M. Sforza, Commercial Airplane Design Principles, 2014.

[24] M. D. Guynn, J. J. Berton, K. L. Fisher et al., "Engine concept study for an advanced single-aisle trans-port," NASA/TM2009-215784, NASA, 2009.

[25] S. Zhang and X. Q. Yu, "Piecewise analytic model for en-route performance of airliners," Flight Dynamics, vol. 30, no. 6, pp. 502-506, 2012.

[26] Liao L. X., Y. P. Ye, and T. H. Dang, "The method and application of the DOC analysis in European market," in Civil Aircraft Design and Research, vol. 1, pp. 1-4, 2013.

[27] ICAO, ICAO Annex 16-Environmental Protection Volume II-Aircraft Engine Emissions, 5th edition, 2008.

[28] A. Dopelheuer and M. Lecht, "Influence of engine performance on emission characteristics Lisbon," in Proceedings of RTO AVT Symposium, Portugal, 1998.

[29] ICAO, ICAO Annex 16-Environmental Protection Volume I-Aircraft Noise, 5th edition, 2008.

[30] L. Bertsch, "Noise Prediction within Conceptual Aircraft Design," DLR Research Report ISRN-DLR-FB-2013-20, DLR Research Report, 2013.

[31] B. J. Clark, "Computer program to predict aircraft noise levels," NASA/TP-1913, NASA, 1981.

[32] K. B. Kontos, B. A. Janardan, P. R. Gliebe et al., "Improved NASA-ANOPP noise prediction computer code for advanced subsonic propulsion systems Volume 2: fan suppression model development," NASA/CR-195480, NASA, 1996.

[33] M. F. Heidmann, "Interim prediction method for fan and compressor source noise," NASA/CR-195480Tech Memo X71763, NASA, 1979.

[34] J. R. Stone, E. A. Krejsa, B. A. Clark et al., "Jet noise modeling for suppressed and unsuppressed aircraft in simulated flight," NASA/TM-2009-215524, NASA, 2009.

[35] M. D. Fink, "Airframe noise prediction method," FAA RD-7729, 1977.

[36] L. Zhao, China, Russia to co-develop widebody jetliner, http:// www.chinadaily.com.cn/bizchina/201509/21/content_21931736 .htm/.
[37] M. Miki, T. Hiroyasu, M. Kaneko et al., "A parallel genetic algorithm with distributed environment scheme," in Proceedings of the IEEE International Conference on Systems, Man, and Cybernetics, pp. 695-700, 1999.

[38] K. Deb, A. Pratap, S. Agarwal, T. Meyarivan et al., "A fast and elitist multiobjective genetic algorithm: NSGA-II," Proceeding of the IEEE Transactions on Evolutionary Computation, vol. 6, no. 2, pp. 182-197, 2002. 


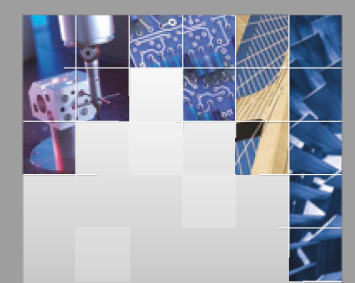

\section{Enfincering}
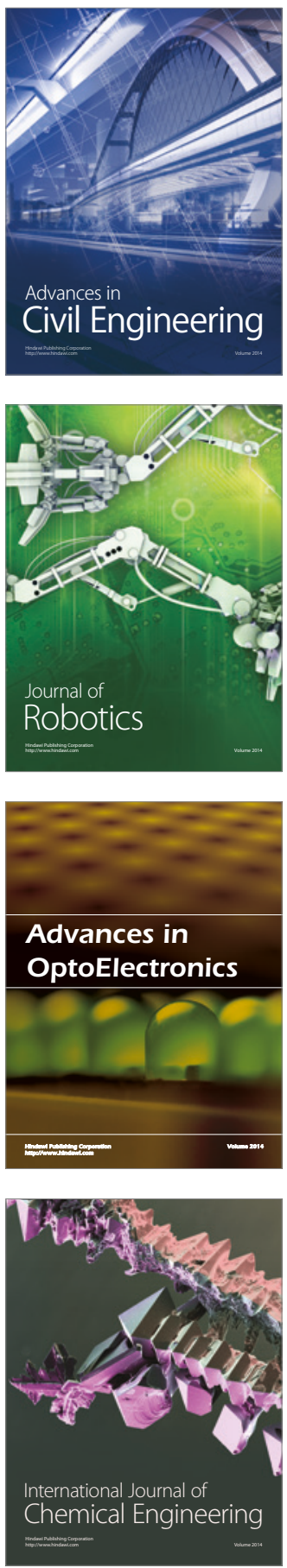

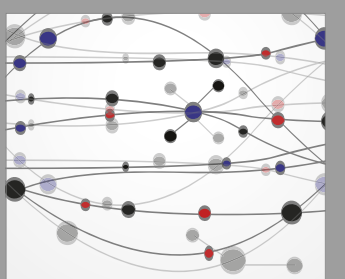

The Scientific World Journal

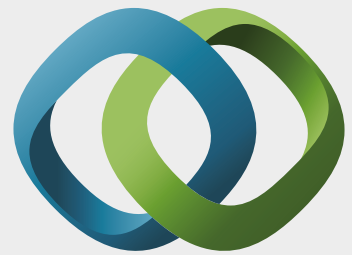

\section{Hindawi}

Submit your manuscripts at

https://www.hindawi.com
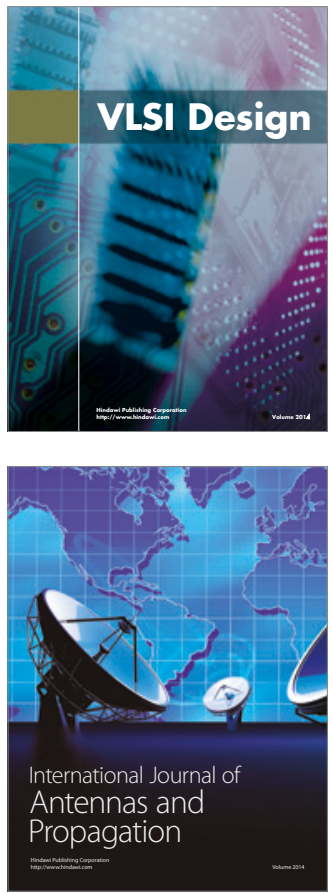

\section{Rotating}

Machinery
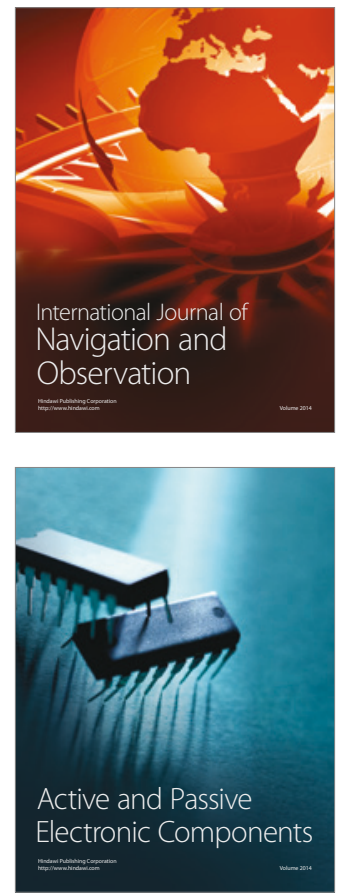
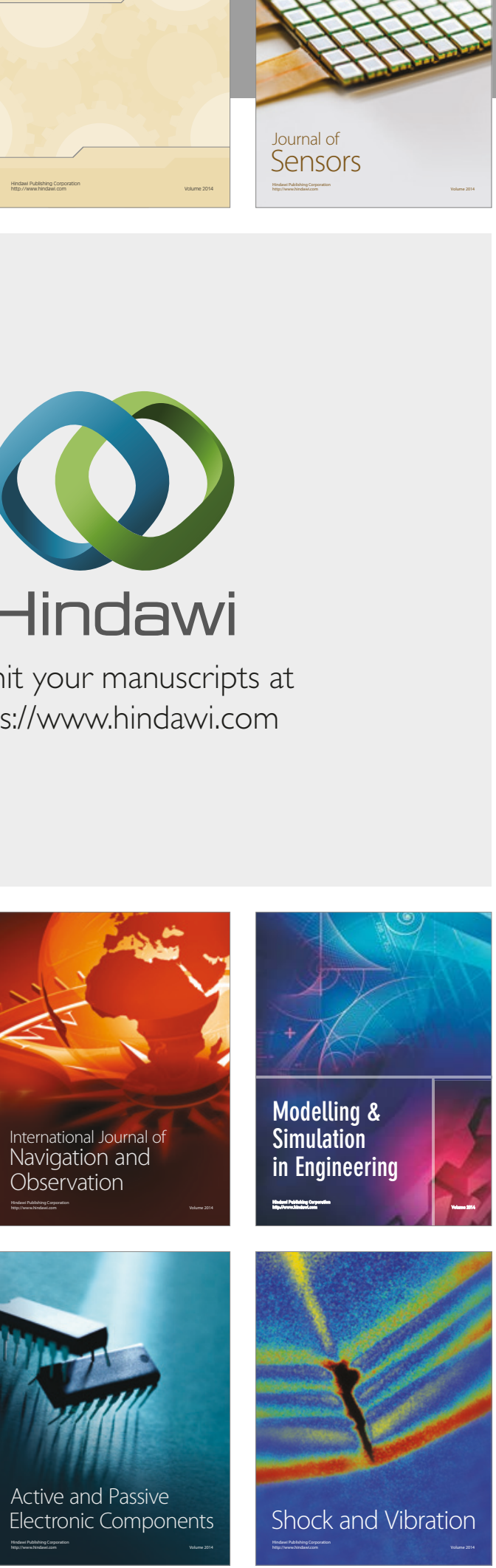
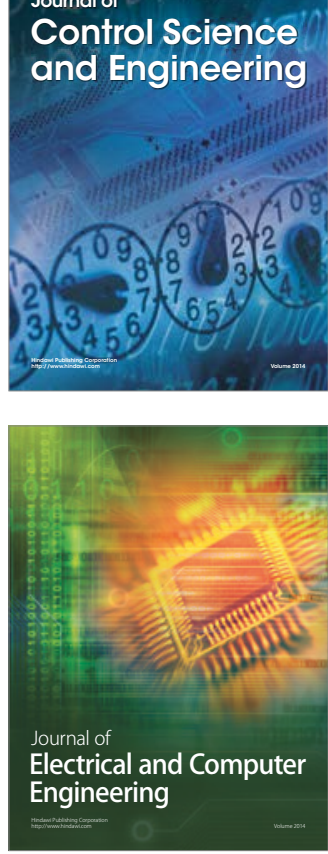

Distributed

Journal of

Control Science

and Engineering
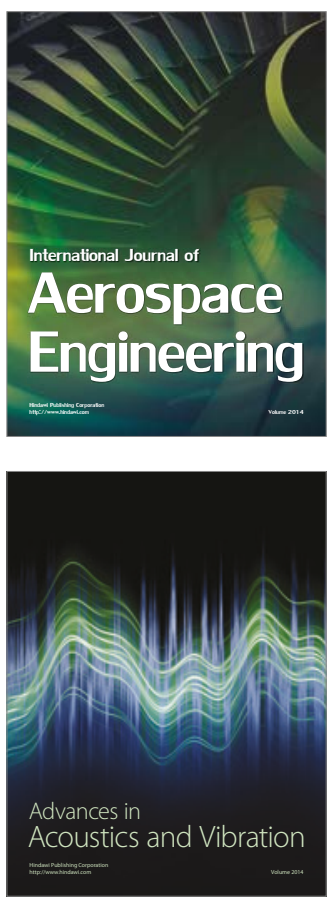

Sensor Networks 